\title{
Synergetic action of ceria nanoparticles and doxorubicin on the early development of two fish species, Danio rerio and Puntius tetrazona
}

\author{
E. Yu. Krysanov ${ }^{1}$, T. B. Demidova ${ }^{1}$, O. S. Ivanova ${ }^{2}$, K. G. Ordzhonikidze ${ }^{3}$, A. B. Shcherbakov ${ }^{4}$, V. K. Ivanov ${ }^{2,5}$ \\ ${ }^{1}$ Severtsov Institute of Ecology and Evolution, Russian Academy of Sciences, Moscow, 119071 Russia \\ ${ }^{2}$ Kurnakov Institute of General and Inorganic Chemistry, Russian Academy of Sciences, Moscow, 119991 Russia \\ ${ }^{3}$ Vavilov Institute of General Genetics, Russian Academy of Sciences, Moscow, 119991 Russia \\ ${ }^{4}$ Zabolotny Institute of Microbiology and Virology,NAS of Ukraine, Kiev, D 03680 Ukraine \\ ${ }^{5}$ National Research Tomsk State University, Tomsk, 634050 Russia \\ krysanov@sevin.ru,van@igic.ras.ru
}

\begin{abstract}
The combined action of ceria nanoparticles and doxorubicin on the early stages of ontogenesis of Danio rerio and Puntius tetrazona was studied. Results obtained indicate that there is a synergetic effect of $\mathrm{CeO}_{2}$ nanoparticles and doxorubicin which is demonstrated by a high incidence of embryonic malformations in fish. This synergetic effect is more pronounced in tiger barbs than in zebrafish, and depends strongly on the synthetic route of ceria nanoparticles' preparation, the most notable effects being registered for citrate-stabilized nanoparticles.
\end{abstract}

Keywords: cerium dioxide, nanotoxicology, zebrafish, doxorubicin, embryotoxicity.

Received: 23 May 2019

Revised: 1 June 2019

\section{Introduction}

Nanoscale cerium oxide (nanoceria) is widely used in modern technological applications as a key component of catalysts, an abrasive, a corrosion inhibitor and a constituent of healthcare and cosmetics products [1,2].

Nanoceria applications in biomedicine have been extensively discussed in several reviews [3-6]. It has been demonstrated that ceria nanoparticles are capable of playing the role of reactive oxygen species (ROS) level regulator and free radicals scavenger, both in vitro and in vivo. The usefulness of nanoceria for biomedical applications can be attributed to two main factors: its oxygen nonstoichiometry and its relatively low toxicity. The first factor determines the ability of nanoceria to affect the redox processes in the living cell, in particular under oxidative stress conditions caused by ROS. The second factor offers the prospect of comparative safety for in vivo applications of ceria nanoparticles.

Another specific property of nanoceria is the ability to regenerate its oxygen nonstoichiometry: after participating in a redox process, ceria nanoparticles are able to return to their initial state in a relatively short period of time; this feature is responsible for a prolonged therapeutic effect of nanosized ceria inside the living body [7].

Current data on nanoceria effects on living beings are still somewhat controversial. Some papers have reported on the pro-oxidant properties of nanoceria [8-10], while others have demonstrated its antioxidant behavior [11-14]. Recent in vitro experiments have demonstrated the fine interplay between the synthesis conditions of nanoceria and its toxicity [15].

The data on nanoceria's effects on aquatic organisms are also quite controversial [16]. Different aquatic species demonstrate different sensitivity rates towards nanoceria. For instance, nanoceria did not show any toxic effects in an acute test with Daphnia magna for concentrations from 10 to $1000 \mathrm{mg} / 1$ [17], yet it appeared to be toxic for two other genus representatives, with significant interspecies differences. Toxicity for D. similis was 350 times as high as for D. pulex [18].

No toxic effects were observed upon microinjection of nanoceria into yolk of Danio rerio embryos [17, 19]. A recent study [20] revealed that $\mathrm{CeO}_{2}$ nanoparticles are non-hazardous to D.rerio embryos, both under visible light and UV-A irradiation; also, nanoceria does not exhibit any UV-A-induced phototoxic effects on zebrafish.

In the majority of papers, the toxic effects were only observed at high concentrations of nanoparticles. In turn, estimated nanoceria concentrations in the environment have been fairly low [21,22], and in aquatic systems the majority of nanoparticles precipitate [23] and only $1.3 \%$ remain suspended in water. For nanoceria concentrations below $1 \mathrm{mg} / \mathrm{l}$, the toxicity has only been observed in one investigation [24]. The technique of suspension preparation also affects toxicity of nanoceria. Suspensions prepared using magnetic stirring did not show any toxic effects in $C$. dubia, while the same suspension prepared under sonication caused death $(\mathrm{EC} 50=11.9-25.3 \mathrm{mg} / \mathrm{l})$ [25]. Another significant 
factor that predetermines toxicity of nanoceria is the composition of precursors for $\mathrm{CeO}_{2}$ synthesis. $\mathrm{CeO}_{2}$ nanoparticles prepared with hexamethylenetetramine (HMT) caused toxic effects in Daphnia during a 48-hour test [26], while HMT itself did not. It should be noted that, in this case, the formation of ceria nanoparticles was accompanied by hydrolysis of HMT, with the release of harmful formaldehyde. Some authors have suggested that nanoceria effects on living organisms depend on the synthesis conditions [4] and type of stabilizers used [27]. For example, in the experiment with fibroblasts, $\mathrm{CeO}_{2}$ nanoparticles stabilized by citrate species interacted more actively with cells and were able to penetrate them [27]. It is worth noting that, in the presence of dissolved organic substances, stability of ceria suspensions increases and aggregate size decreases [17, 28,29]. It is fair to assume that synergetic effects of nanoceria and dissolved ecotoxic agents may also be observed in a natural water environment.

The present paper aims to investigate the synergetic action of $\mathrm{CeO}_{2}$ nanoparticles and doxorubicin on the early stages of fish ontogenesis. The effects of antibiotics on the early stages of embryogenesis have been quite well investigated. Doxorubicin is a strong cardiotoxin, and the choice of doxorubicin in our experiments was due to the fact that its cardiotoxic effect is easily observable and can be distinguished from the effects caused by nanoparticles [30]. As the toxic effects of nanoceria-doxorubicin composition can exhibit interspecies differences, we used two fish species in our study, namely zebrafish (Danio rerio) and tiger barb (Puntius tetrazona), whose embryogenesis features are different.

\section{Materials and methods}

We used three types of ceria nanoparticle, including two aqueous sols and water-dispersible nanopowder. A nonstabilized $6 \mathrm{~nm}$ ceria aqueous sol was synthesized using a previously reported technique of hydrothermal-microwave treatment of the colloid solution formed upon anionite treatment of a cerium (III) nitrate aqueous solution [31]. Briefly, Amberlite IRA $410 \mathrm{CL}$ ion-exchange resin (Aldrich, \#216569), preliminarily converted to the $\mathrm{OH}$-form, was gradually added to a $0.01 \mathrm{M}$ cerium (III) nitrate (Aldrich, \#238538) solution until $\mathrm{pH}$ reached 10.0. Sols formed in this way were separated from the resin by filtering, immediately transferred to $100 \mathrm{ml}$ polytetrafluoroethylene autoclaves (filled to $50 \%$ ) and subjected to hydrothermal-microwave treatment in a Berghof Speedwave MWS-3+ setup at $190{ }^{\circ} \mathrm{C}$ for $3 \mathrm{~h}$. Upon completion of the synthesis, the autoclaves were withdrawn from the microwave oven and cooled down to room temperature in air. A citrate-stabilized ceria sol was obtained from the "naked" one by addition of an equimolar quantity of citric acid, and through careful neutralizing of the solution with ammonia (Chimmed, Russia). In addition, $\mathrm{a} \mathrm{CeO}_{2}$ nanopowder was used (Sigma Aldrich, particle size $<25 \mathrm{~nm}$ ).

Lyophilized doxorubicin hydrochloride powder (Pharmachemi, Netherlands) was purchased from a local distributor.

Particle size measurements by dynamic light scattering and $\zeta$-potential measurements by automatic titration were carried out on the Malvern Zetasizer Nano ZS analyser (Malvern Instruments, UK). The light source used was a helium-neon laser, (the radiation wavelength was $632.8 \mathrm{~nm}$ ).

Tests were carried out in zebrafish (Danio rerio) and tiger barb (Puntius tetrazona) embryos. The fish were kept under standard conditions in 20 litre aquaria at $26^{\circ} \mathrm{C}$ with a $12 \mathrm{~h} \mathrm{light} / 12 \mathrm{~h}$ dark time-schedule. The eggs were collected immediately after spawning; the quality was estimated under a stereomicroscope. The embryos were incubated in embryo media ( $5 \mathrm{mmol} \mathrm{NaCl} ; 0.17 \mathrm{mmol} \mathrm{KCl} ; 0.33 \mathrm{mmol} \mathrm{CaCl}_{2} ; 0.33 \mathrm{mmol} \mathrm{MgSO}_{4} ; \mathrm{pH}=7.2-7.3$ ) in 24-well plates.

In a preliminary experiment, we assessed the action of pure doxorubicin (concentrations from 0.1 to $50 \mathrm{mg} / \mathrm{l}$ ) on the development of zebrafish using ceria nanoparticles alone $(0.001,0.01,0.1,1.0$ and $10 \mathrm{mg} / \mathrm{l})$, doxorubicin alone $(1.0,5.0,10,20,30$ and $50 \mathrm{mg} / \mathrm{l})$ and mixtures of nanoparticles and doxorubicin, wherein a single concentration of doxorubicin $(10 \mathrm{mg} / \mathrm{l})$ was used with nanoceria sols of different concentrations (from 0.001 to $10 \mathrm{mg} / \mathrm{l}$ ), or a single concentration of nanoceria sols $(10 \mathrm{mg} / \mathrm{l})$ was used with 1.0 and $5.0 \mathrm{mg} / \mathrm{l}$ of doxorubicin.

For the preparation of the $\mathrm{CeO}_{2}$ nanoparticle suspension, the necessary quantity of stock colloidal solution of $\mathrm{CeO}_{2}$ was dispersed in an embryo medium by sonication for $10 \mathrm{~min}$. Doxorubicin stock solution was prepared in distilled water. The nanoparticle suspension was mixed with fresh doxorubicin solution immediately after preparation, with subsequent sonication for $2 \mathrm{~min}$.

The embryo development stages were examined using a stereomicroscope (Carl Zeiss, Stemi 2000C) and were matched according to [32].

\subsection{Developmental biology of zebrafish and barb eggs}

Barb eggs have a sticky layer, for substrate affixing, which hardens after fertilization. The eggs are transparent. Development up to hatching lasts for $24 \mathrm{~h}$ at $28{ }^{\circ} \mathrm{C}$. The yolk sack resolves in $58-72 \mathrm{~h}$ after hatching. The embryogenesis period in barbs, when the embryo remains inside the egg and is protected by chorion, is shorter than with 
zebrafish ( $24 \mathrm{~h}$ for the barb and $72 \mathrm{~h}$ for zebrafish). However, the larval period, when the larva swims but does not eat, is longer in tiger barbs than in zebrafish.

Fertilized eggs were collected in the first two hours after spawning. Embryos were transferred to a 24-well plate containing $2 \mathrm{ml}$ of the solution being tested per well. Each embryo was transferred to a separate well and 24 embryos were used per test concentration. Embryos were incubated in a culture medium containing $0.29 \mathrm{~g} / 1 \mathrm{NaCl}, 0.013 \mathrm{~g} / \mathrm{l}$ $\mathrm{KCl}, 0.05 \mathrm{~g} / \mathrm{l} \mathrm{CaCl} 2 \times 7 \mathrm{H}_{2} \mathrm{O}, 0.0365 \mathrm{~g} / \mathrm{C} \mathrm{CaCl}_{2}, 0.815 \mathrm{~g} / \mathrm{MgCl}_{2} \times 6 \mathrm{H}_{2} \mathrm{O} ; 7.0-7.5 \mathrm{pH}$. Embryos were kept in an incubator at $26{ }^{\circ} \mathrm{C}$ with a $14 \mathrm{~h}$ light $/ 10 \mathrm{~h}$ dark time-schedule. The medium was not replaced during the course of the experiment. Embryos were tested daily using a Zeiss Stemi 2000 stereomicroscope. Malformations and other teratogenic effects were scored. Survival rate, percentage of malformed embryos and rate of hatching were calculated at $96 \mathrm{hpf}$.

Statistical analysis was performed using a Chi-Square test in an SPSS 21 data analysis package.

\section{Results}

\section{Doxorubicin toxicity in fish}

Doxorubicin toxicity was assessed for concentrations of 0.1 to $50 \mathrm{mg} / \mathrm{l}$. A significant increase in embryo death was registered for concentrations of $40 \mathrm{mg} / \mathrm{l}$ and higher (Fig. 1(a)). The death rate was $91.7 \%$ for a concentration of $40 \mathrm{mg} / \mathrm{l}$. Embryonic abnormalities began to increase at concentrations starting from $30 \mathrm{mg} / \mathrm{l}$ (Fig. 1(b)). Pericardial edema was one of the most frequent types among the registered abnormalities. For this reason, for subsequent tests, we chose a doxorubicin concentration of $10 \mathrm{mg} / \mathrm{l}$, for which the rate of embryonic abnormalities and mortality did not differ significantly from that for the control group.

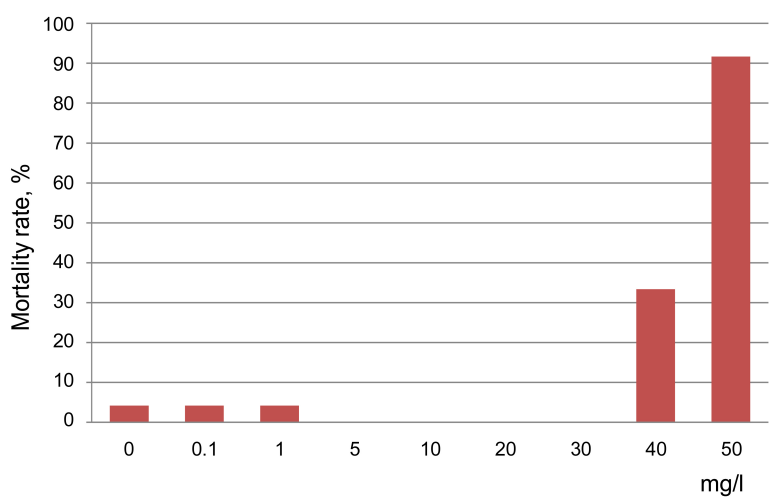

(a)

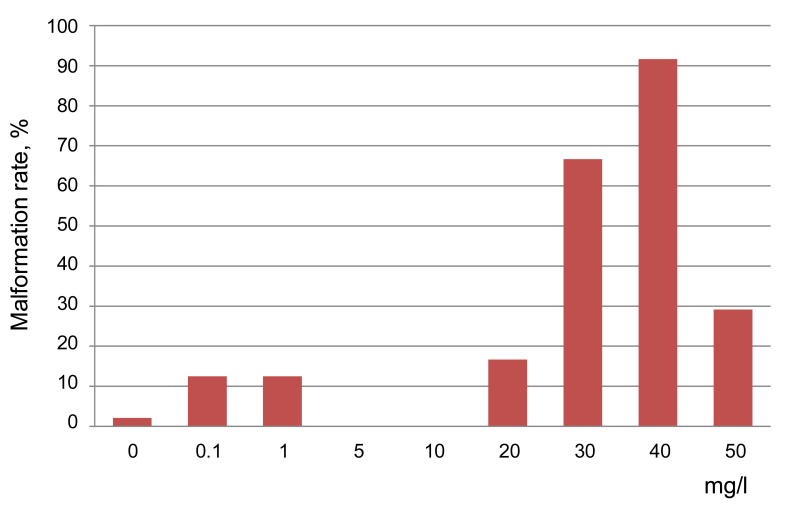

FIG. 1. Mortality rate (a) and malformation rate (b) of zebrafish embryos on exposure to different concentrations of doxorubicin

\section{5. $\mathrm{CeO}_{2}$ nanoparticles colloids and suspensions toxicity for Danio rerio embryos}

Our data indicate that $\mathrm{CeO}_{2}$ nanoparticles in a concentration of $10 \mathrm{mg} / \mathrm{l} \mathrm{did} \mathrm{not,} \mathrm{themselves,} \mathrm{affect} \mathrm{zebrafish}$ embryonic development (Fig. 2). The survival rate did not differ from that for the control group, and was independent of the method of nanoparticle preparation (Fig. 2(a)). The rate of malformations also did not exceed the control group 
rate (Fig. 2(b)). Ceria nanoparticles also did not affect hatching time. Hatching started in 48 hours and finished in 72 hours. No significant differences between ceria-treated and control groups were registered (Fig. 3).

(a)
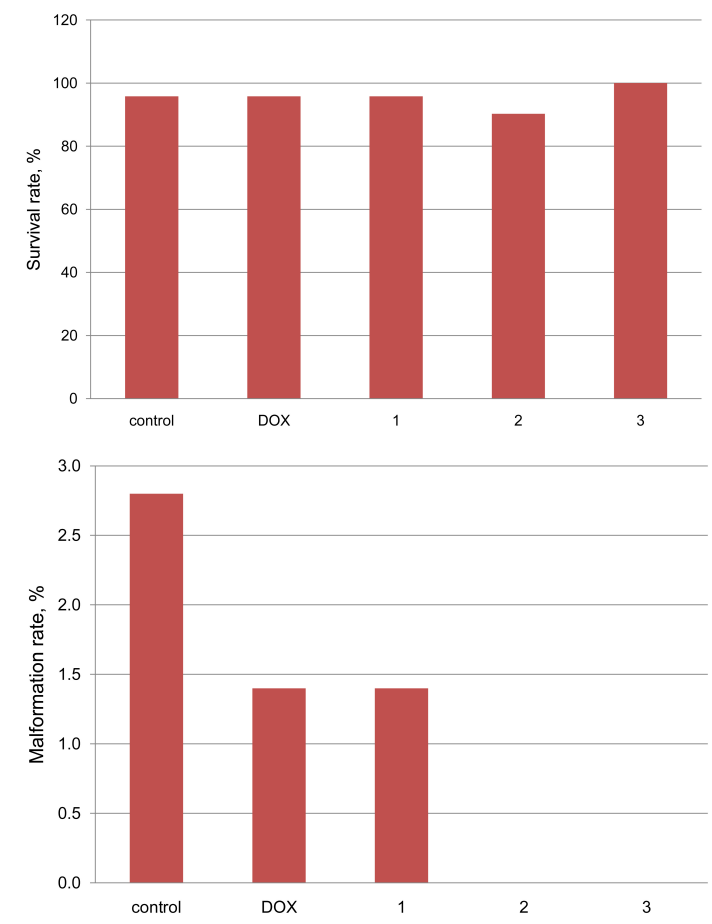

FIG. 2. Danio rerio embryo survival rates (a) and the rate of Danio rerio embryos with developmental abnormalities (b) on exposure to doxorubicin or ceria nanoparticles $(10 \mathrm{mg} / \mathrm{l})$. DOX doxorubicin, 1 - citrate-stabilized ceria, 2 - non-stabilized ceria, 3 - ceria nanopowder

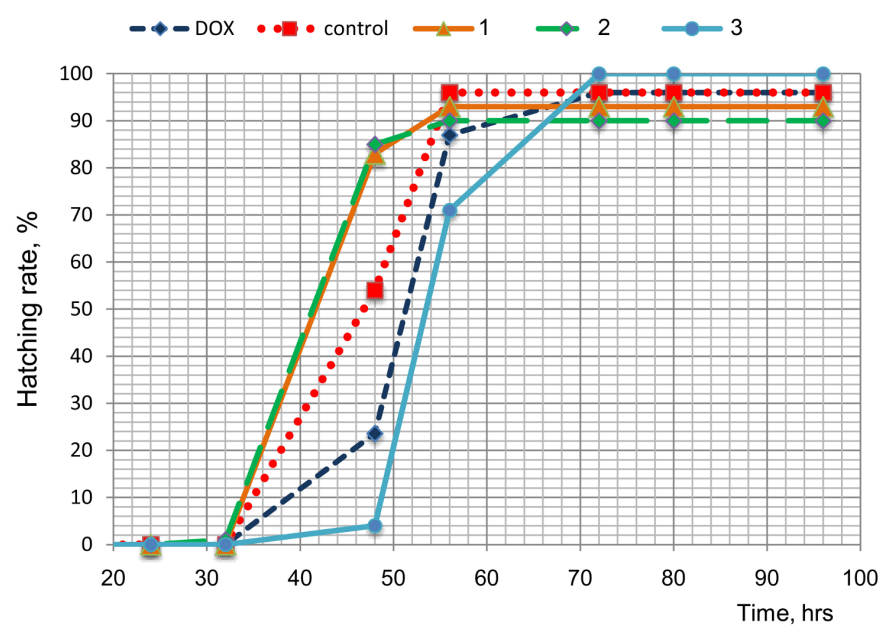

FIG. 3. Hatching rate of Danio rerio embryos upon exposure to doxorubicin or ceria nanoparticles $(10 \mathrm{mg} / \mathrm{l})$. DOX - doxorubicin, 1 - citrate-stabilized ceria, 2 - non-stabilized ceria, 3 - ceria nanopowder

\subsection{The synergetic effects of various $\mathrm{CeO}_{2}$ concentrations and fixed doxorubicin concentration $(10 \mathrm{mg} / \mathrm{l})$}

For the assessment of possible synergetic effects, $\mathrm{CeO}_{2}$ nanoparticles in concentrations from 0.001 to $10 \mathrm{mg} / \mathrm{l}$ were mixed with doxorubicin $(10 \mathrm{mg} / \mathrm{l})$. Various combinations of nanoceria and doxorubicin had no significant effect on either zebrafish or tiger barb embryo survival rates (Fig. 4). In turn, the rate of malformations began to increase as 
the ceria concentrations increased (Fig. 5). This effect was observed for all types of ceria nanoparticles and for both species of fish. The majority of abnormalities were represented by pericardial edema.

(a)
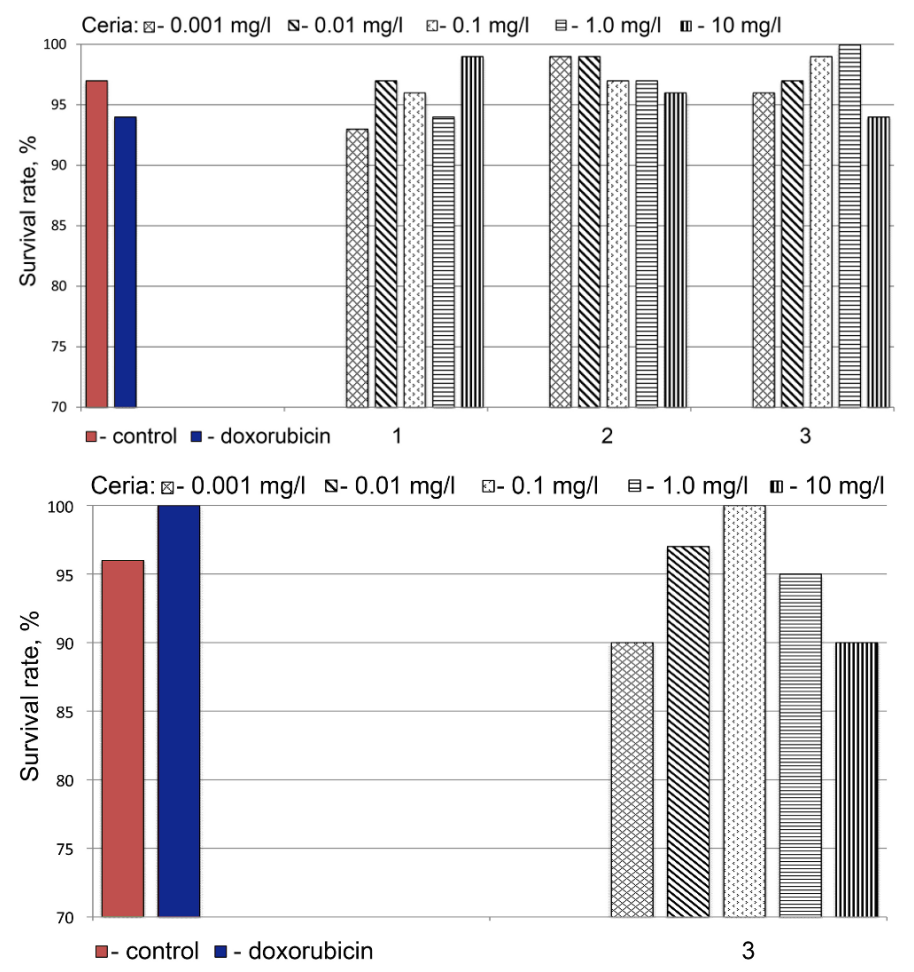

FIG. 4. The survival rate of zebrafish (D. rario) (a) and of tiger barb (P. tetrazona) (b) embryos on exposure to doxorubicin alone $(10 \mathrm{mg} / \mathrm{l})$ and the mixture of ceria nanoparticles $(0.001-10 \mathrm{mg} / \mathrm{l})$ with doxorubicin (10 mg/l), $N=72$ (a), $N=40$ (b). 1 - citrate-stabilized ceria, 2 - non-stabilized ceria, 3 - ceria nanopowder

There was a significant difference between the effects of various types of ceria nanoparticles on zebrafish embryos. For the citrate-stabilized $\mathrm{CeO}_{2}$ sol, a significant increase in abnormalities was noted, even for a concentration of $1 \mathrm{mg} / \mathrm{l}$ $(15.3 \%)$, while, at a $\mathrm{CeO}_{2}$ concentration of $10 \mathrm{mg} / \mathrm{l}$, the rate of malformations increased to $98.6 \%$. For the nonstabilized cerium dioxide sol at a concentration of $10 \mathrm{mg} / \mathrm{l}$, the abnormality rate also increased, compared with the control group $(51.4 \%)$, but it was significantly lower than for citrate-stabilized nanoceria. The addition of the ceria nanopowder caused only minimal effects on the malformation rate; the malformation rate exceeded that caused by doxorubicin alone, but was lower than for $\mathrm{CeO}_{2}$ sols (31.9\%), with statistically significant differences.

In the experiments with the tiger barbs, only $\mathrm{CeO}_{2}$ nanopowder mixed with doxorubicin was used. Increasing the concentration of $\mathrm{CeO}_{2}$ to $10 \mathrm{mg} / \mathrm{l}$ caused a rise in embryonic abnormality rate to $90 \%$. Thus, significant differences in the ceria nanopowder-doxorubicin mixture effects were revealed for two different species of fish, with the malformation rate higher for the tiger barbs.

The high malformation rate did not affect the hatching of surviving embryos; the rate of hatched larvae exceeded $90 \%$ for all groups (Fig. 6(a, b, c, d)). No significant differences were observed, either for the rate of hatched larvae or for the hatching time period.

\subsection{Synergetic effects of a fixed concentration of ceria nanoparticles $(10 \mathrm{mg} / \mathrm{l})$ and various concentrations of doxorubicin ( 1 and $5 \mathrm{mg} / \mathrm{l}$ ) on the embryonic development of zebrafish}

For the next experimental series, ceria nanoparticles, at a concentration of $10 \mathrm{mg} / \mathrm{l}$, were mixed with doxorubicin $(1.0$ or $5.0 \mathrm{mg} / \mathrm{l})$. The data obtained demonstrate that survival and malformation rates and the hatching success of zebrafish upon exposure to low concentrations of doxorubicin mixed with ceria did not differ significantly from the control and doxorubicin alone groups (Table 1).

Thus, low doxorubicin concentrations in combination with high $\mathrm{CeO}_{2}$ nanoparticle concentrations had no significant effects on zebrafish embryo development. 
(a)
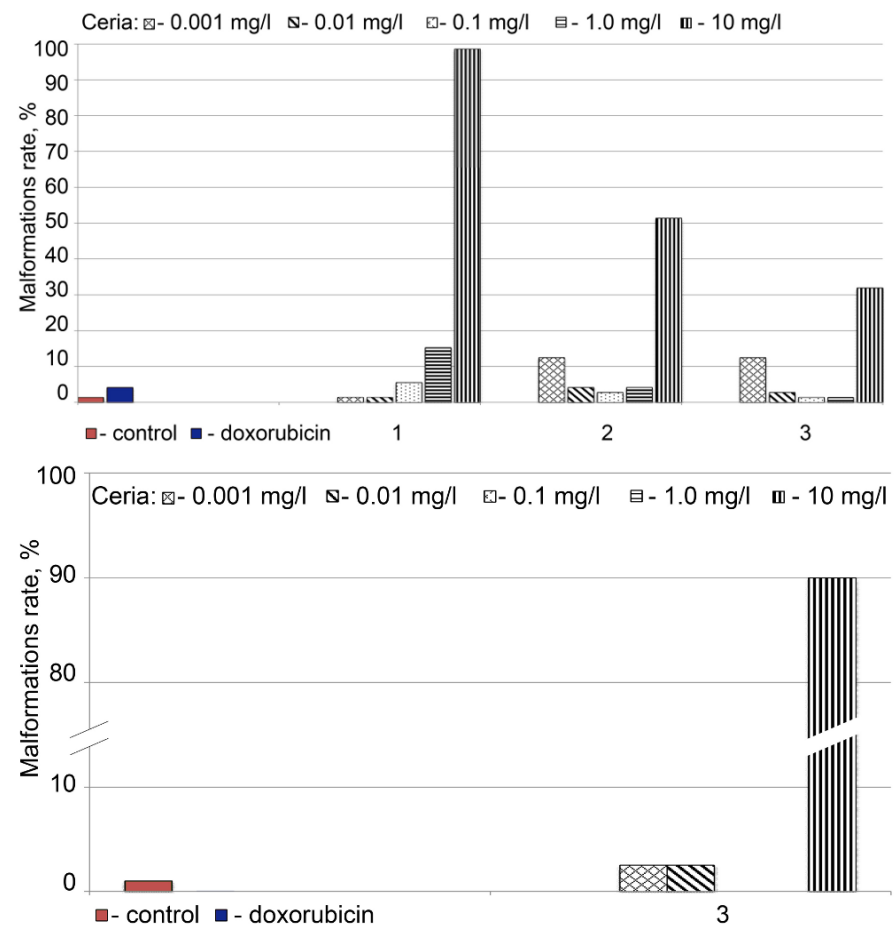

FIG. 5. The malformation rate in the embryonic development of zebrafish (a) and tiger barbs (b) on exposure to doxorubicin alone $(10 \mathrm{mg} / \mathrm{l})$ and the mixture of ceria nanoparticles $(0.001-10 \mathrm{mg} / \mathrm{l})$ with doxorubicin (10 mg/l), $N=72$ (a), $N=40$ (b). 1 - citrate-stabilized ceria, 2 - non-stabilized ceria, 3 - ceria nanopowder

\section{Discussion}

Data obtained indicate that, regardless of the preparation method and stabilizer type, ceria nanoparticles alone in concentrations ranging from 0.001 to $10 \mathrm{mg} / \mathrm{l}$ did not demonstrate any toxic effects during acute tests in zebrafish. The survival rate of embryos, hatching success and malformation rate did not exceed control significantly. The data

TABLE 1. The effects of different types of $\mathrm{CeO}_{2}$ nanoparticles $(10 \mathrm{mg} / \mathrm{l})$ and doxorubicin on zebrafish embryos

\begin{tabular}{|c|c|c|c|c|c|c|c|c|c|}
\hline & \multirow[b]{2}{*}{$\begin{array}{l}\overline{0} \\
\bar{\Xi} \\
\dot{0}\end{array}$} & \multirow[b]{2}{*}{ 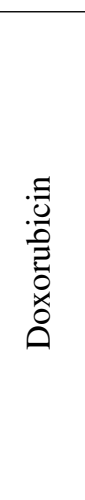 } & \multicolumn{2}{|c|}{$\begin{array}{c}\text { Citrate-stabilized } \\
\text { ceria }\end{array}$} & \multicolumn{2}{|c|}{$\begin{array}{l}\text { Non-stabilized } \\
\text { ceria }\end{array}$} & \multicolumn{3}{|c|}{ Ceria nanopowder } \\
\hline & & & 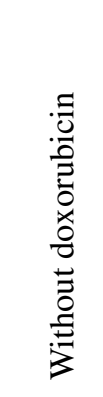 & 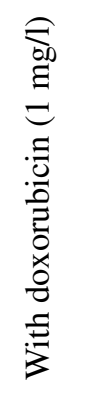 & $\begin{array}{l}\text { : } \\
00 \\
0 \\
\overline{0} \\
0 \\
0 \\
0 \\
0 \\
0 \\
0 \\
0\end{array}$ & 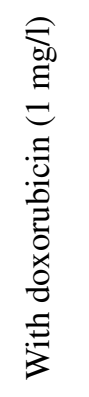 & 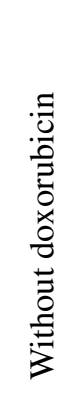 & 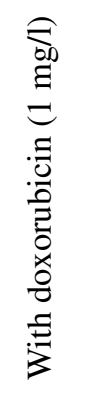 & 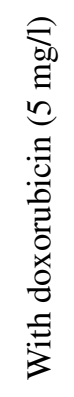 \\
\hline$N$ & 72 & 72 & 48 & 48 & 48 & 48 & 24 & 24 & 24 \\
\hline mortality & 4.2 & 1.4 & 4.2 & 8.3 & 4.2 & 2.1 & 0 & 5.6 & 5.6 \\
\hline malformations & 1.4 & 0 & 2.1 & 0 & 0 & 0 & 0 & 2.8 & 1.4 \\
\hline hatching & 95.1 & 97.9 & 89.6 & 91.7 & 95.8 & 95.8 & 100 & 93.1 & 94.4 \\
\hline
\end{tabular}




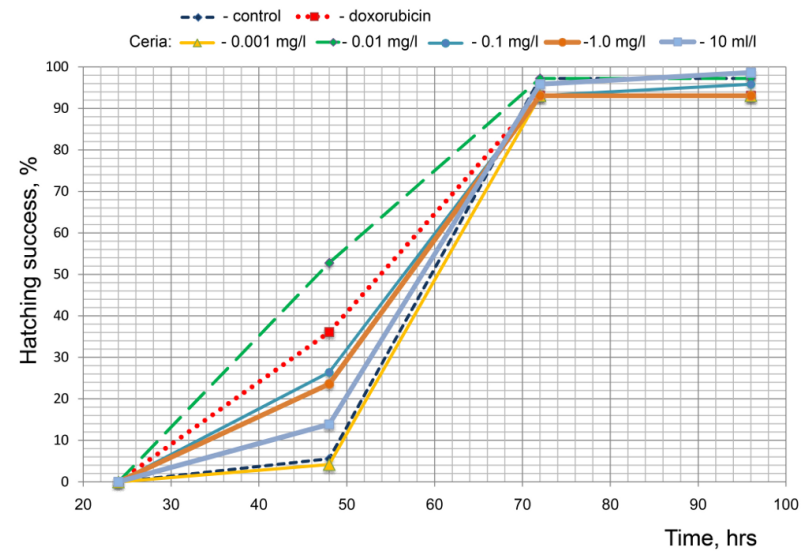

(a)

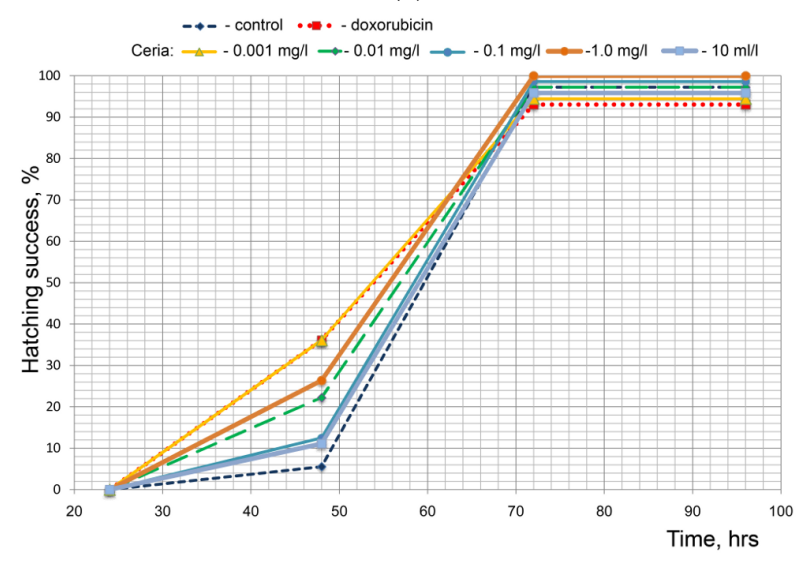

(c)

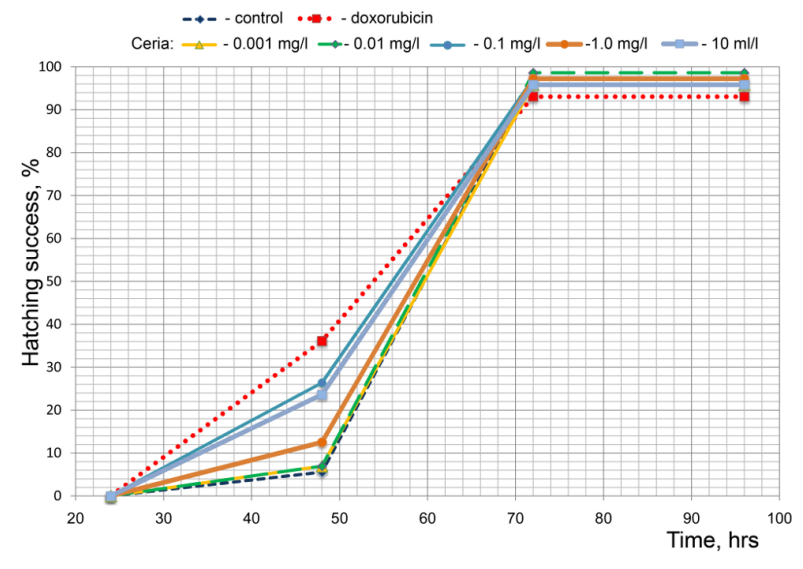

(b)

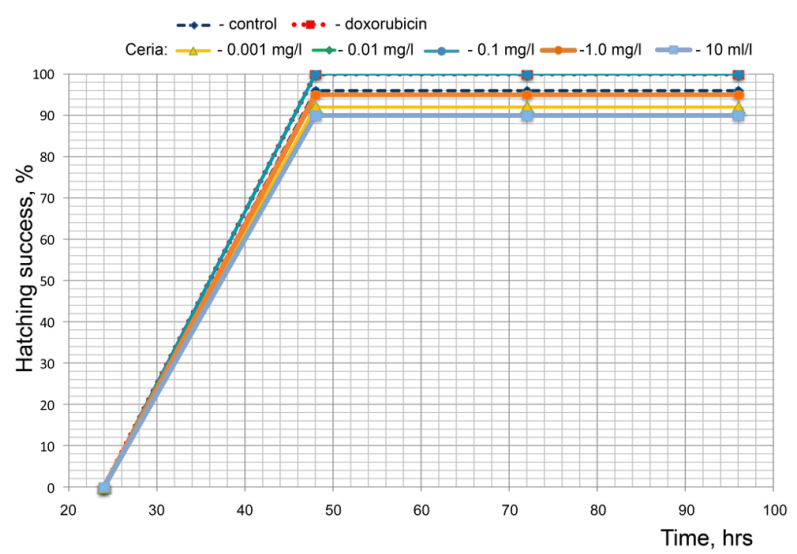

(d)

FIG. 6. The hatching success of zebrafish (a, b, c) and tiger barb (d) embryos on exposure to a mixture of citrate-stabilized ceria nanoparticles $(0.001-10 \mathrm{mg} / \mathrm{l})(\mathrm{a})$, non-stabilized ceria nanoparticles $(0.001-10 \mathrm{mg} / \mathrm{l})(\mathrm{b})$ and ceria nanopowder $(0.001-10 \mathrm{mg} / \mathrm{l})(\mathrm{c}, \mathrm{d})$ with doxorubicin $(10 \mathrm{mg} / \mathrm{l})$ $(N=72$ for $(\mathrm{a}, \mathrm{b}, \mathrm{c})$ and $N=40$ for $(\mathrm{d}))$

obtained agree with data derived for zebrafish embryos and ceria nanoparticles at concentrations of 13 to $200 \mathrm{mg} / \mathrm{l}$ [17]. However, it was previously shown that $\mathrm{TiO}_{2}$ nanoparticles which were non-toxic in an acute test [33] influenced the behavior of larvae in a chronic test at nanoparticle concentrations of $1 \mathrm{mg} / \mathrm{l}$ [34]. Therefore, our data cannot exclude the possibility of chronic toxicity of nanoceria in fish.

The presence of ecotoxic agents in an aqueous environment can considerably influence the nanoparticle behavior and their effects on aquatic species. It has been shown in previous studies that metal oxide nanoparticles can increase the accumulation of diluted ecotoxicants in aquatic species or cause a synergetic effect. For example, in experiments on adult fish, the presence of $\mathrm{TiO}_{2}$ nanoparticles in water at a concentration of $10 \mathrm{mg} / \mathrm{l}$ increased As and Cd accumulation in carp (Cyprinus carpio) up to $30-140 \%[35,36]$. However, in the experiments on zebrafish, with the same $\mathrm{TiO}_{2}$ nanoparticles, at concentrations of $5-20 \mathrm{mg} / \mathrm{l}$, no pronounced influence on Cd bioaccumulation was observed [37]. Similar results were obtained in Daphnia sp. The presence of $2 \mathrm{mg} / 1 \mathrm{TiO}_{2}$ nanoparticles increased Cd accumulation six-fold in D. magna. For $\mathrm{TiO}_{2}$ nanoparticles, the increase in $\mathrm{Cu}^{2+}$ accumulation and toxicity was also observed for D. magna [38]; the same effect was registered for $\mathrm{As}^{5+}$ accumulation in C. dubia [39]. Similarly, the introduction of $\mathrm{CeO}_{2}$ nanoparticles increased atrazine accumulation in Daphnia due to herbicide adsorption and transfer by the nanoparticles [40].

In the present study, doxorubicin was used as a model ecotoxic agent. Doxorubicin is known to have cardiotoxic effects on zebrafish development [41], and leads to embryonic malformations, including pericardial edema, in concentrations exceeding $10 \mathrm{mg} / \mathrm{l}$. Doxorubicin concentrations were used which do not affect zebrafish development. Addition of ceria nanoparticles did not lead to embryonic death, but had a significant effect on doxorubicin toxicity. When mixed with all types of ceria nanoparticles $(10 \mathrm{mg} / \mathrm{l})$, doxorubicin taken in $10 \mathrm{mg} / \mathrm{l}$ concentration caused a 
significant rise in embryonic malformations, mainly pericardial oedema. Lower concentrations of ceria nanoparticles in the mixtures did not lead to such effects.

It is well known that metal oxide nanoparticles in aqueous solutions easily adsorb molecules and ions of various organic and inorganic substances. Due to its specific chemical properties, cerium dioxide appears to be a very good sorbent for several substances. For instance, $\mathrm{CeO}_{2}$ nanoparticles adsorb $58 \%$ of an initial concentration of $\mathrm{Pb}^{2+}$, which is considerably higher than for $\mathrm{TiO}_{2}$ and $\mathrm{Fe}_{3} \mathrm{O}_{4}$ nanoparticles [42]. Furthermore, $\mathrm{CeO}_{2}$ nanoparticles are good adsorbents for various antibiotics, due to their affinity to hydrophilic molecules [43]. Apparently, in experiments conducted for the current research, ceria nanoparticles could adsorb doxorubicin and consequently promote the increase in its local concentration in zebrafish chorion. This effect was registered only for certain concentrations of doxorubicin and $\mathrm{CeO}_{2}$ nanoparticles in the media.

Malformation rate in tiger barbs during embryogenesis was significantly higher than in zebrafish. Enhanced sensitivity of barb embryos is most likely to appear due to a shorter incubation period of the embryo in the egg: in contrast with zebrafish, the barb hatches within $24 \mathrm{hpf}$.

The question is still open as to whether the effects observed were caused by ceria nanoparticle penetration into the chorion. It has been established previously that silica nanoparticles do not penetrate zebrafish chorion [44]. Similarly, upon keeping zebrafish in the nanoceria-containing media, approximately $37 \%$ of ceria nanoparticles bind with the chorion and only $0.07 \%$ get through [45].

Citrate-stabilized cerium dioxide sols mixed with doxorubicin appeared to have the most toxic effect. A minimal effect was observed for suspended ceria nanopowders. An intermediate effect was registered for non-stabilized cerium dioxide sols.

Results obtained can be explained taking into account the peculiarities of doxorubicin adsorption on ceria nanoparticles. The interaction in the adsorption system depends on the charge of both adsorbent and adsorbate; the electrostatic difference potential of doxorubicin is unevenly distributed among functional groups, thus the position of functional groups will determine the orientation of the molecule. Calculations made indicate two possible orientations of a doxorubicin molecule on the ceria surface - vertical and planar (see Appendix, Fig. A1). In the first case, interaction with the surface proceeds via a nitrogen group, which has a positive charge when protonated. Obviously, this orientation will be favorable on the negatively charged surface. In the second case, interaction of the molecule with the surface proceeds via the $\pi$-electron system of fused aromatic rings and acidic - $\mathrm{OH}$ phenol groups, having a negative charge when doxorubicin is ionized. This "flat" orientation of doxorubicin is favorable on the positively charged surface, wherein the molecule occupies the area corresponding to about eight cerium atoms. According to calculations of the electronic structure [46], the sum of the atomic partial charges of the isolated molecule of doxorubicin is zero; in the aquatic environment, the total charge of the molecule is slightly positive, and in complex with DNA is slightly negative, but the overall pattern of the charge distribution is the same.

Unlike weak electrostatic adsorption on gold [47], citric acid is strongly chemisorbed on the ceria surface and cannot be substituted by doxorubicin; the interaction of doxorubicin with citrate-stabilized ceria occurs via the layer of citric acid molecules. The citrate adsorbs on the surface in an ordered manner (see Appendix, Fig. A2(A)), and the grafting density is one citrate molecule per $3-4 \mathrm{Ce}$ atoms. Our data indicate that "citrate-stabilized" ceria nanoparticles have negative $\zeta$-potential in the whole range of biologically relevant $\mathrm{pH}$ values. In turn, for "naked" ceria nanoparticles, the $\zeta$-potential typically has a positive charge in the range of $\mathrm{pH}<8$ (see Appendix, Fig. A3). Several authors have shown that the interaction of various citrate-coated nanoparticles with organic molecules including doxorubicin can proceed by formation of hydrogen bonds [48] or by more complicated surface interactions [49]. According to the calculation referred to above, the doxorubicin molecule would preferably have a vertical orientation on the surface of a nanoparticle coated with dissociated carboxylic groups. In this case, the nitrogen atom of the antibiotic interacted with the carboxyl group of the citrate. Fig. A2(B) shows that the grafting density of doxorubicin on a citrate-coated ceria surface is one molecule per $4-5 \mathrm{Ce}$ atoms. Some of the citric acid molecules did not participate in the interaction with the antibiotic; these molecules assure the colloidal stability of ceria nanoparticles.

The fraction of atoms located on the surface of a nanoparticle strongly depends on its size. The corresponding dependence for nanoceria is shown in Figs. A4 and A5. For $6 \mathrm{~nm}$ ceria nanoparticles, the proportion of surface-located atoms is about $40 \%$; for $25 \mathrm{~nm}$ nanoceria, about $12 \%$. The amount of adsorbed doxorubicin molecules for these types of nanoparticles varies correspondingly. For example, $10 \mathrm{mg}$ of citrate-coated ceria nanoparticles can adsorb $2.8 \mathrm{mg}$ of doxorubicin; $10 \mathrm{mg}$ of the same "naked" ceria nanoparticles can adsorb $1.58 \mathrm{mg}$ of doxorubicin; $10 \mathrm{mg}$ of ceria nanopowder can adsorb $0.47 \mathrm{mg}$ of doxorubicin (see Appendix). As the present work has demonstrated, the toxicity of doxorubicin-ceria conjugated changes in the same manner: citrate-coated nanoceria > "naked" nanoceria > ceria nanopowder.

Results obtained demonstrated that there exists a synergetic effect of ceria nanoparticles and doxorubicin action; the effect was expressed in a high incidence of embryonic malformations in fish. This effect was more pronounced in 
tiger barbs than in zebrafish, which, in the authors' opinion, was due to some peculiarities of their embryogenesis. It was also found that differently prepared $\mathrm{CeO}_{2}$ nanoparticles demonstrated different efficiency. Thus, $\mathrm{CeO}_{2}$ stable sols application had a stronger effect than a suspended nanopowder. The method of nanoceria stabilization also played a considerable role in the synergetic action of nanoparticles and doxorubicin. Citrate-stabilized cerium dioxide nanoparticles had significantly higher effects than non-stabilized nanoparticles. A certain minimum ratio of nanoparticles and doxorubicin had to be reached to provide a synergetic effect, which substantially depended on the cerium surface atoms available, i.e. on the nanoparticles' size and on the presence of the stabilizer.

Ceria nanoparticles (both non-stabilized and citrate-stabilized aqueous colloid solutions and water redispersible ceria nanopowder) have no embryotoxic effect on Danio rerio and Puntius tetrazona. Nevertheless, nanoceria has been shown to increase greatly the toxic effect of doxorubicin on fish embryogenesis. This synergetic effect of ceria nanoparticles and doxorubicin depends strongly on the concentration of components, as well as on particle size and the presence of a stabilizer.

\section{Acknowledgements}

This work was partially supported by research grants of Russian foundation for Basic Research No. 18-29$05023 \mathrm{mk}$.

\section{References}

[1] Adachi G., Imanaka N., Kang Z.C. Binary Rare Earth Oxides. Kluwer Academic Publishers, Dordrecht, 2005,133 p.

[2] Trovarelli A. Catalysis by Ceria and Related Materials. Imperial College Press, London, 2002, 58 p.

[3] Ivanov V.K., Shcherbakov A.B., Usatenko A.V. Structure-Sensitive Properties and Biomedical Applications of Nanodispersed Cerium Dioxide. Russ. Chem. Rev., 2009, 78 (9), P. 855-871.

[4] Karakoti A., Singh S., et al. Redox-Active Radical Scavenging Nanomaterials. Chem. Soc. Rev., 2010,39 (11), 4422.

[5] Shcherbakov A.B., Ivanov V.K., et al. Nanocrystalline Ceria Based Materials - Perspectives for Biomedical Application. Biophysics (Oxf)., 2011, 56 (6), P. 987-1004.

[6] Das S., Dowding J.M., et al. Cerium Oxide Nanoparticles: Applications and Prospects in Nanomedicine. Nanomedicine, 2013, 8 (9), P. 14831508.

[7] Shcherbakov A.B., Zholobak N.M., Spivak N.Y., Ivanov V.K. Advances and Prospects of Using Nanocrystalline Ceria in Cancer Theranostics. Russ. J. Inorg. Chem., 2014, 59 (13), P. 1556-1575.

[8] Park E.-J., Choi J., Park Y.-K., Park K. Oxidative Stress Induced by Cerium Oxide Nanoparticles in Cultured BEAS-2B Cells. Toxicology, 2008, 245 (1-2), P. 90-100.

[9] Horie M., Nishio K., et al. Cellular Responses Induced by Cerium Oxide Nanoparticles: Induction of Intracellular Calcium Level and Oxidative Stress on Culture Cells. J. Biochem., 2011, 150 (4), P. 461-471.

[10] Tseng M.T., Lu X., et al. Alteration of Hepatic Structure and Oxidative Stress Induced by Intravenous Nanoceria. Toxicol. Appl. Pharmacol., 2012, 260 (2), P. 173-182.

[11] Lee S.S., Song W., et al. Antioxidant Properties of Cerium Oxide Nanocrystals as a Function of Nanocrystal Diameter and Surface Coating. ACS Nano, 2013, 7 (11), P. 9693-9703.

[12] Karakoti A.S., Monteiro-Riviere N.A., et al. Nanoceria as Antioxidant: Synthesis and Biomedical Applications. JOM, 2008 , 60 (3), P. 33-37.

[13] Hirst S.M., Karakoti A., et al. Bio-Distribution and in Vivo Antioxidant Effects of Cerium Oxide Nanoparticles in Mice. Environ. Toxicol., 2013, 28 (2), P. 107-118.

[14] Chigurupati S., Mughal M.R., et al. Effects of Cerium Oxide Nanoparticles on the Growth of Keratinocytes, Fibroblasts and Vascular Endothelial Cells in Cutaneous Wound Healing. Biomaterials, 2013, 34 (9), P. 2194-2201.

[15] Karakoti A.S., Munusamy P., et al. Preparation and Characterization Challenges to Understanding Environmental and Biological Impacts of Ceria Nanoparticles. Surf. Interface Anal., 2012, 44 (8), P. 882-889.

[16] Cassee F.R., van Balen E.C., et al. Exposure, Health and Ecological Effects Review of Engineered Nanoscale Cerium and Cerium Oxide Associated with Its Use as a Fuel Additive. Crit. Rev. Toxicol., 2011, 41 (3), P. 213-229.

[17] Van Hoecke K., De Schamphelaere K.A.C., et al. Aggregation and Ecotoxicity of $\mathrm{CeO}_{2}$ Nanoparticles in Synthetic and Natural Waters with Variable PH, Organic Matter Concentration and Ionic Strength. Environ. Pollut., 2011, 159 (4), P. 970-976.

[18] Artells E., Issartel J., et al. Exposure to Cerium Dioxide Nanoparticles Differently Affect Swimming Performance and Survival in Two Daphnid Species. PLoS One, 2013, 8 (8), e71260.

[19] Arnold M.C., Badireddy A.R., et al. Cerium Oxide Nanoparticles Are More Toxic than Equimolar Bulk Cerium Oxide in Caenorhabditis Elegans. Arch. Environ. Contam. Toxicol., 2013, 65 (2), P. 224-233.

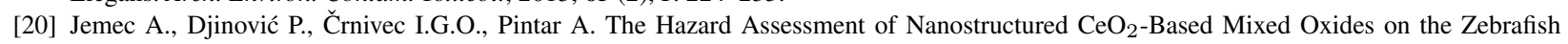
Danio Rerio under Environmentally Relevant UV-A Exposure. Sci. Total Environ., 2015, 506-507, P. $272-278$.

[21] O’Brien N., Cummins E. Nano-Scale Pollutants: Fate in Irish Surface and Drinking Water Regulatory Systems. Hum. Ecol. Risk Assess. An Int. J., 2010, 16 (4), P. 847-872.

[22] Johnson A.C., Park B. Predicting Contamination by the Fuel Additive Cerium Oxide Engineered Nanoparticles within the United Kingdom and the Associated Risks. Environ. Toxicol. Chem., 2012, 31 (11), P. 2582-2587.

[23] Zhang P., He X., et al. Distribution and Bioavailability of Ceria Nanoparticles in an Aquatic Ecosystem Model. Chemosphere, 2012, 89 (5), P. 530-535.

[24] Bottero J.-Y., Auffan M., et al. Manufactured Metal and Metal-Oxide Nanoparticles: Properties and Perturbing Mechanisms of Their Biological Activity in Ecosystems. Comptes Rendus Geosci., 2011, 343 (2-3), P. 168-176. 
[25] Manier N., Garaud M., et al. Behaviour of Ceria Nanoparticles in Standardized Test Media - Influence on the Results of Ecotoxicological Tests. J. Phys. Conf. Ser., 2011, 304, 012058.

[26] García A., Espinosa R., et al. Acute Toxicity of Cerium Oxide, Titanium Oxide and Iron Oxide Nanoparticles Using Standardized Tests. Desalination, 2011, 269 (1-3), P. 136-141.

[27] Ould-Moussa N., Safi M., et al. In Vitro Toxicity of Nanoceria: Effect of Coating and Stability in Biofluids. Nanotoxicology, 2014, 8 (7), P. 799-811.

[28] Quik J.T.K., Lynch I., et al. Effect of Natural Organic Matter on Cerium Dioxide Nanoparticles Settling in Model Fresh Water. Chemosphere, 2010, 81 (6), P. 711-715.

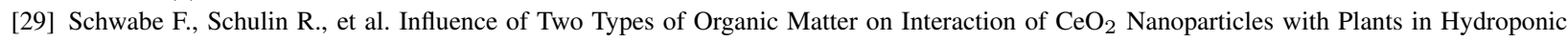
Culture. Chemosphere, 2013, 91 (4), P. 512-520.

[30] Han Y., Zhang J., Qian J., Hu C. Cardiotoxicity Evaluation of Anthracyclines in Zebrafish ( Danio Rerio ). J. Appl. Toxicol., 2015, 35 (3), P. 241-252.

[31] Ivanov V.K., Polezhaeva O.S., et al. Microwave-Hydrothermal Synthesis of Stable Nanocrystalline Ceria Sols for Biomedical Uses. Russ. J. Inorg. Chem., 2010, 55 (1), P. 1-5.

[32] Kimmel C.B., Ballard W.W., et al. Stages of Embryonic Development of the Zebrafish. Dev. Dyn., 1995, 203 (3), P. $253-310$.

[33] Zhu X., Zhu L., et al. Comparative Toxicity of Several Metal Oxide Nanoparticle Aqueous Suspensions to Zebrafish (Danio Rerio) Early Developmental Stage. J. Environ. Sci. Heal. Part A, 2008, 43 (3), P. 278-284.

[34] Chen T.-H., Lin C.-Y., Tseng M.-C. Behavioral Effects of Titanium Dioxide Nanoparticles on Larval Zebrafish (Danio Rerio). Mar. Pollut. Bull., 2011, 63 (5-12), P. 303-308.

[35] Sun H., Zhang X., et al. Enhanced Accumulation of Arsenate in Carp in the Presence of Titanium Dioxide Nanoparticles. Water. Air. Soil Pollut., 2007, 178 (1-4), P. 245-254.

[36] Zhang X., Sun H., et al. Enhanced Bioaccumulation of Cadmium in Carp in the Presence of Titanium Dioxide Nanoparticles. Chemosphere, 2007, 67 (1), P. 160-166.

[37] Hu X., Chen Q., et al. Combined Effects of Titanium Dioxide and Humic Acid on the Bioaccumulation of Cadmium in Zebrafish. Environ. Pollut., 2011, 159 (5), P. 1151-1158.

[38] Fan W., Cui M., et al. Nano-TiO 2 Enhances the Toxicity of Copper in Natural Water to Daphnia Magna. Environ. Pollut., 2011, 159 (3), P. 729-734.

[39] Wang D., Hu J., Irons D.R., Wang J. Synergistic Toxic Effect of Nano-TiO 2 and As(V) on Ceriodaphnia Dubia. Sci. Total Environ., 2011, 409 (7), P. 1351-1356.

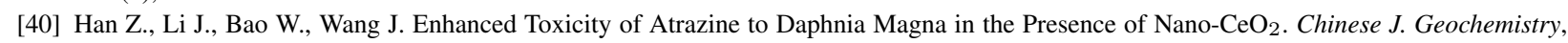
2012, 31 (3), P. 297-302.

[41] Chang C., Wu S.L., et al. Developmental Toxicity of Doxorubicin Hydrochloride in Embryo-Larval Stages of Zebrafish. Biomed. Mater. Eng., 2014, 24 (1), P. 909-916.

[42] Recillas S., Garca A., et al. Use of $\mathrm{CeO}_{2}, \mathrm{TiO}_{2}$ and $\mathrm{Fe}_{3} \mathrm{O}_{4}$ Nanoparticles for the Removal of Lead from Water. Desalination, 2011,277 (1-3), P. 213-220.

[43] Brigante M., Schulz P.C. Adsorption of the Antibiotic Minocycline on Cerium(IV) Oxide: Effect of PH, Ionic Strength and Temperature. Microporous Mesoporous Mater., 2012, 156, P. 138-144.

[44] Fent K., Weisbrod C.J., Wirth-Heller A., Pieles U. Assessment of Uptake and Toxicity of Fluorescent Silica Nanoparticles in Zebrafish (Danio Rerio) Early Life Stages. Aquat. Toxicol., 2010, 100 (2), P. 218-228.

[45] Felix L.C., Ortega V.A., Ede J.D., Goss G.G. Physicochemical Characteristics of Polymer-Coated Metal-Oxide Nanoparticles and Their Toxicological Effects on Zebrafish (Danio Rerio) Development. Environ. Sci. Technol., 2013, 47 (12), P. $6589-6596$.

[46] Poudel L., Wen A.M., et al. Electronic Structure and Partial Charge Distribution of Doxorubicin in Different Molecular Environments. Chem. Phys. Chem., 2015, 16 (7), P. 1451-1460.

[47] Curry D., Cameron A., et al. Adsorption of Doxorubicin on Citrate-Capped Gold Nanoparticles: Insights into Engineering Potent Chemotherapeutic Delivery Systems. Nanoscale, 2015, 7 (46), P. 19611-19619.

[48] Nawara K., Romiszewski J., et al. Adsorption of Doxorubicin onto Citrate-Stabilized Magnetic Nanoparticles. J. Phys. Chem. C, 2012, 116 (9), P. 5598-5609.

[49] Auffan M., Masion A., et al. Long-Term Aging of a $\mathrm{CeO}_{2}$ Based Nanocomposite Used for Wood Protection. Environ. Pollut., 2014, 188, P. 1-7. 


\section{Appendix}
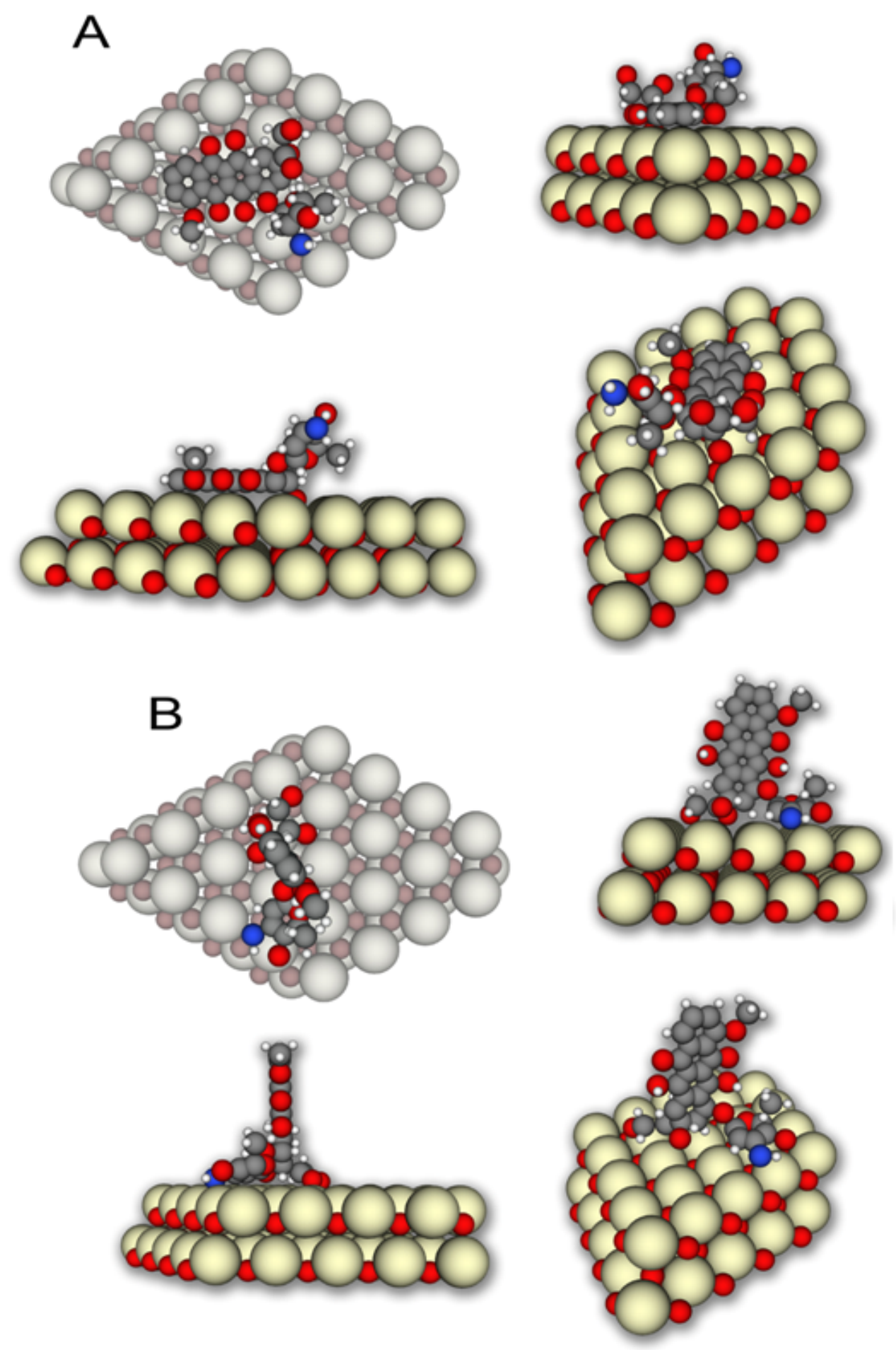

FIG. A1. The calculated adsorption of a doxorubicin molecule on the surface of a ceria cluster: A planar orientation; B - vertical orientation 

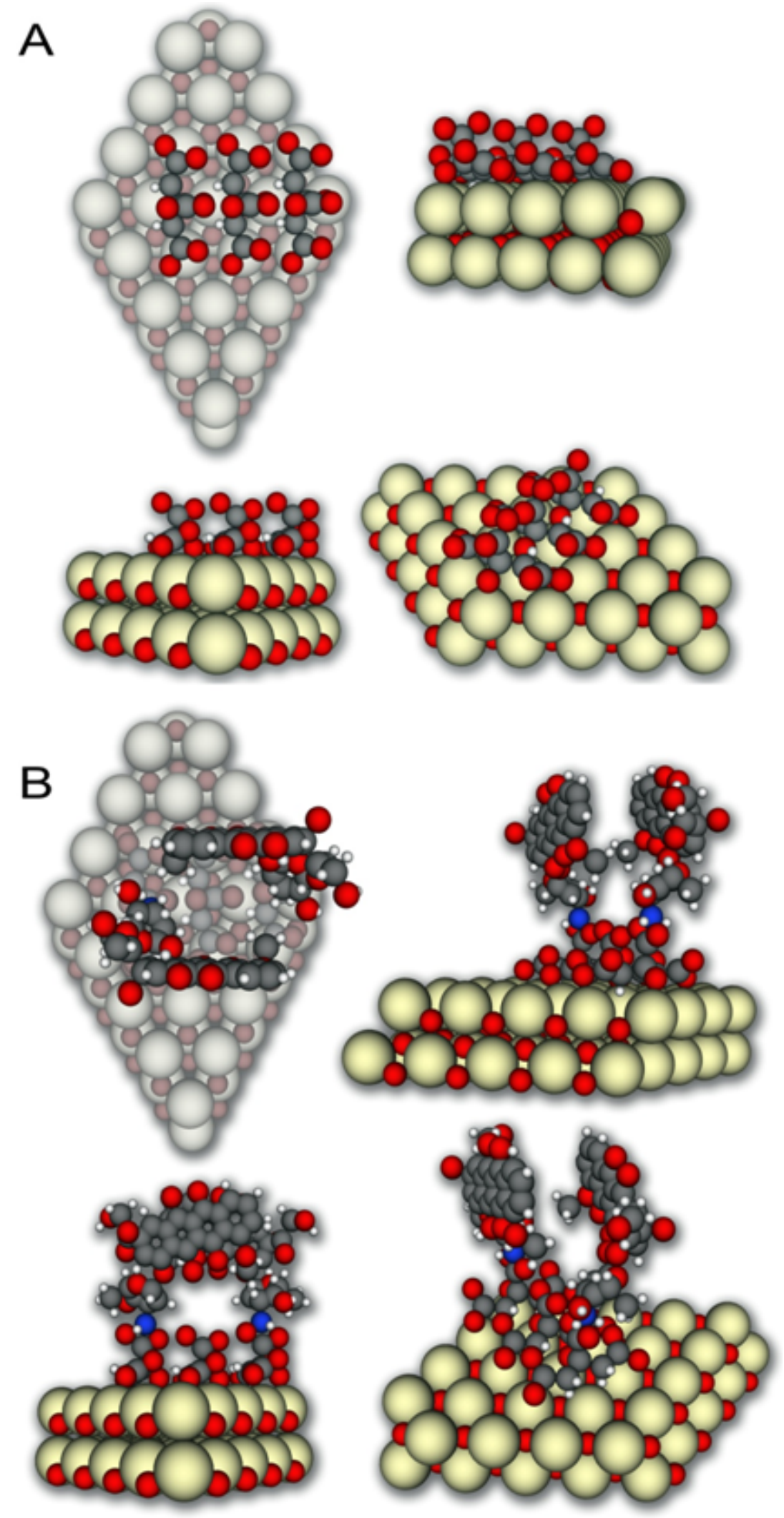

FIG. A2. The calculated adsorption of citrate molecules on the surface of a ceria cluster (A) and doxorubicin molecules on a citrate-coated surface of a ceria cluster (B) 


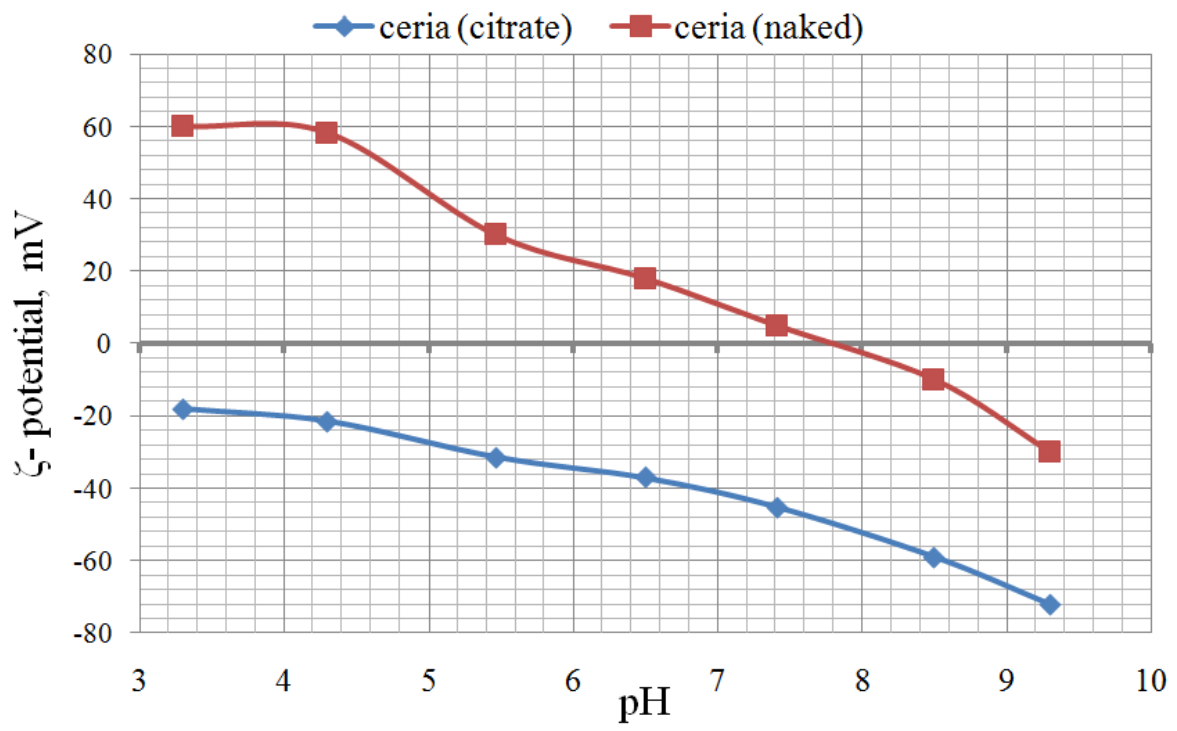

FIG. A3. The dependence of the $\zeta$-potential of the "naked" and citrate-stabilized ceria nanoparticles on $\mathrm{pH}$

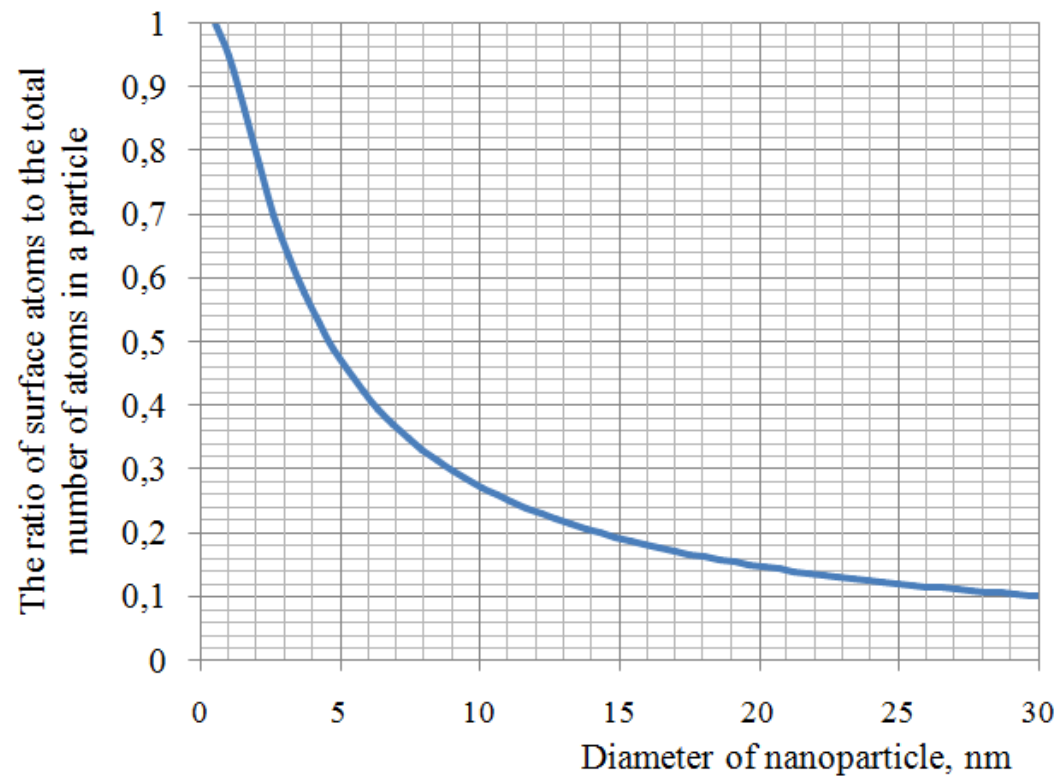

FIG. A4. The calculated ratio of surface atoms to the total number of atoms as a function of ceria particle size 

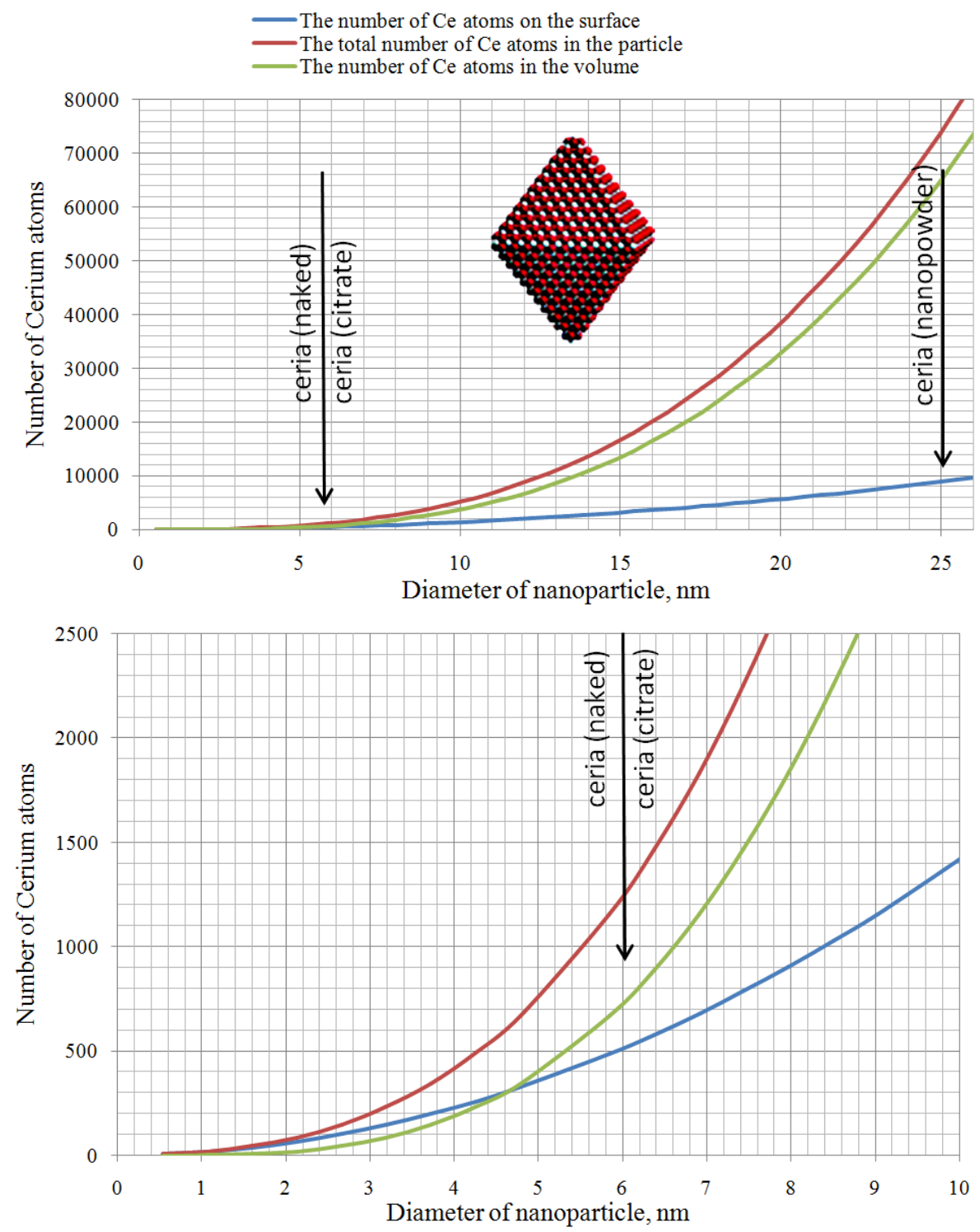

FIG. A5. The calculated number of surface and bulk cerium atoms in octahedral-shaped $\mathrm{CeO}_{2}$ nanoparticles as a function of particle size

Calculation of doxorubicin amount which could be adsorbed on $10 \mathrm{mg}$ of cerium dioxide particles.

where

$$
M=10 / M W_{\mathrm{CeO}_{2}} \cdot R / S \cdot M W_{D o x}=31.6 \cdot R / S,
$$

$M-$ the amount of doxorubicin, $\mathrm{mg}$;

$M W_{\mathrm{CeO}_{2}}$ - the molecular weight of ceria, $172 \mathrm{~g} / \mathrm{mol}$;

$R$ - the fraction of the cerium atoms at the surface of the particle;

$S$ - the "landing area" (the number of cerium atoms occupied by one molecule or grafting density) of doxorubicin;

$\mathrm{MW}_{\text {Dox }}$ - the molecular weight of doxorubicin, $543.5 \mathrm{~g} / \mathrm{mol}$.

"ceria (citrate)" ( size $6 \mathrm{~nm}), R=0.4, S=4-5, M \approx 2.8 \mathrm{mg}$ of doxorubicin;

"ceria (naked)" (size $6 \mathrm{~nm}), R=0.4, S=8, M=1.58 \mathrm{mg}$ of doxorubicin;

"ceria (nanopowder)" (size $24 \mathrm{~nm}), R=0.12, S=8, M=0.47 \mathrm{mg}$ of doxorubicin. 